\section{Dr Thomas Denman of London (1733-1815): rupture of the membranes and management of the cord}

\author{
P M Dunn
}

Born in 1733 Thomas Denman was the son of an apothecary in Bakewell, Derbyshire. He was educated locally and, after the death of his father in 1752, assisted his elder brother with the practice. In 1754 , at the age of 21 , he travelled to London to study anatomy at St George's Hospital. Within a year he ran out of money and so joined the Navy as a ship's surgeon. After eight years, with funds derived in part from the sale of French prizes captured off West Africa, he returned to St George's Hospital where he attended the lectures of Dr William Smellie. A year later, in 1764, having obtained an $\mathrm{MD}$ in Aberdeen, he entered practice in the City. He was also at this time appointed surgeon to the royal yacht William $\mathcal{E}$ Mary - worth $£ 70$ a year. In 1769 he was made man-midwife to the Middlesex Hospital, a post he held for the next 14 years. Also, in collaboration with Dr Osborn, he gave lectures at St George's Hospital. After Dr William Hunter's death in 1783 Thomas Denman became the leading British obstetrician and thereafter limited himself to his large consulting practice. That same year he was admitted Licentiate in Midwifery of the College of Physicians, among the first to be so admitted, and also published a successful book on Aphorism on the Application and Use of Forceps and Vectis.... ${ }^{1}$ An even greater success was to follow, his magnum opus $A n$ Introduction to the Practice of Midwifery, first published in 1794 but running through seven editions during the next 38 years. The extracts that follow in this article are taken from the third edition ${ }^{2}$ which has been described by Dr Herbert Spencer as 'perhaps the most splendid work on midwifery in the English language whether regarded from the point of view of the format, paper, printing and illustrations of the work; the learning and knowledge that it exhibits; or the ordered, lucid, and judicial manner in which that knowledge is presented. ${ }^{3}$

Through his writing and teaching Denman probably wielded a greater influence upon English midwifery than that of any of his predecessors with the possible exceptions of Smellie and Hunter. He was greatly respected for his wisdom and sound judgment. His practice was conservative, for he placed great reliance on the natural process of childbirth, while not hesitating to intervene when neces-

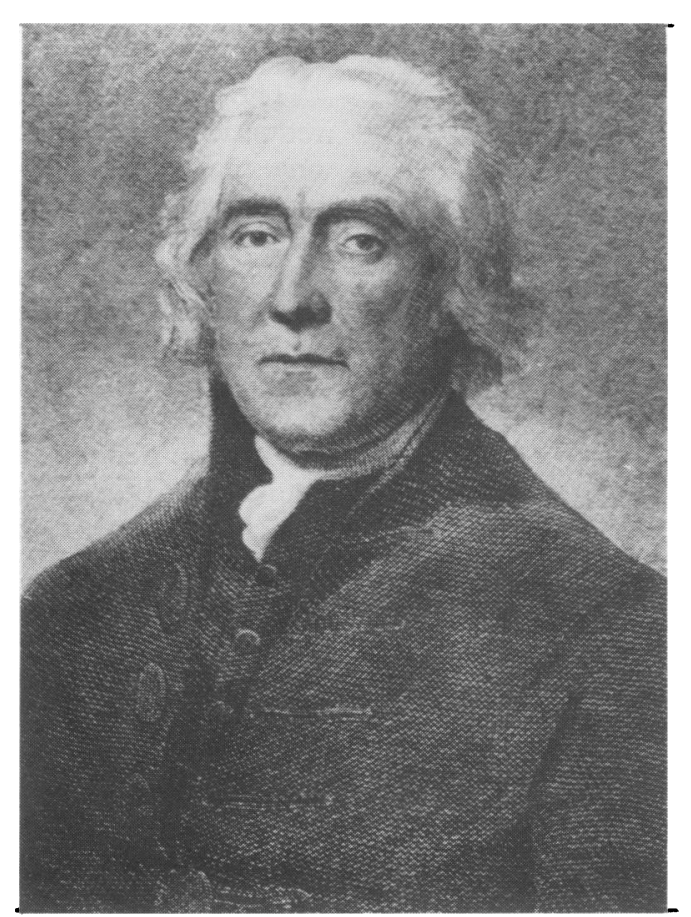

Dr Thomas Denman, 1733-1815.

sary. This approach is revealed in his discussion of surgical premature rupture of the membranes which he warned against, while at the same time indicating that it might occasionally be necessary in order to induce labour either as a means of avoiding disproportion or to save the life of the fetus.

\section{On rupture of the membranes}

'The premature rupture of the membranes, whether natural or artificial, has been often mentioned as the cause of much mischief, and of many tedious or difficult labours. If it be allowed, that the membranes containing the waters were intended to be the medium by which the os uteri, and other tender parts, ought to be dilated, some inconvenience must arise when these are broken and the waters discharged, the head of the child being substituted for them; and this, being a firmer and less accommodating body, cannot for a long time, be admitted within the circle of the os uteri, which will of necessity be dilated more untowardly and more painfully'. 
'...it is in common observation, that far the greater number of those labours which have been considered as difficult, and which really were such towards the conclusion, were not in fact occasioned by the absolute state of the patient, but by interposition, and the desire of accelerating labours, which in their nature required a certain time for their completion. This interposition has chiefly consisted of two points of practice, both extremely reprehensible; the artificial dilation of the os uteri, and the premature rupture of the membranes. By such practice the order of the labour becomes disarranged, and there often follow occasions to exercise art, for the relief of those evils which were originally caused by the improper use of art, to the great hazard of the parent or child. So long therefore as labours proceed naturally, they may be proper objects of our observation, reason, and judgment, but cannot be considered as the objects of art. Yet when they are proved to be beyond the efforts of nature to accomplish, the assistance of art becomes justifiable because it is necessary, and we may be reconciled to the fate of the child, if the life of the mother cannot possibly be preserved by any means consistent with its safety'.

'There is another situation in which I have proposed, and tried with success, the method of bringing on premature labour. Some women, who readily conceive, proceed regularly in their pregnancy till they approach the full period, when, without any apparently adequate cause, they have been repeatedly seized with rigor, and the child has instantly died, though it may not have been expelled for some weeks afterwards. In two cases of this kind I have proposed to bring on premature labour, when I was certain the child was living, and have succeeded in preserving the children without hazard to the mothers'.

Denman's book is rich in observations and comments that are still of interest and reference today. The second subject chosen for inclusion in this short article is on:

\section{Management of the umbilical cord}

'There is yet in all things a perfectly right as well as a wrong method; and, though the advantage or disadvantage of either may be overlooked, the propriety and advantage of the right method must be evidently proved by individual cases, and of course by the general result of practice. In this, as well as in many other points, we have been too fond of interfering with art, and have consigned too little to nature, as if the human race had been destined to wretchedness and disaster, from the moment of birth, beyond the allotment of other creatures.

Perhaps the changes which take place in the body of the child, immediately after its birth, at least the manner in which they are produced, are not perfectly understood at this time. But we know if the child is in a healthy state, that it usually cries lustily and continually, when the air rushes into its lungs, which are thereby expanded. This cry, which does not seem to be occasioned by pain but surprise, is in its consequences extremely important, as it is the cause of an exertion of all the powers of the child, and enables it to acquire a new manner of living, inconsistent with, and very different from, that which is possessed before it was born. But the change from uterine life, as it may be called, to breathing life, is not instantaneous, but gradual; and the uterine life continues till the breathing life is perfected, as is proved by the continuance of the circulation between the child and placenta for some time after it has cried. As the breathing life becomes perfected, the uterine life gradually declines, and the manner of its declention may be proved by attending to the pulsation of the navel-string, which first ceases at the part nearest the placenta, and then, by slow degrees, nearer and nearer to the child, till at length it entirely ceases; so that the whole of the circulating blood ultimately resides in the body of the child, and the navel-string becomes quite flaccid. It seems reasonable to believe, that the continuance of the uterine life after the birth of the child was designed for its preservation from the accidents of its state at that time, should the acquisition of its breathing life be by any cause retarded or hindered. If then the practice of tying or dividing the navel-string the instant the child is born be followed, though it were before vigorous, it will in some cases immediately decline, and, never acquiring its perfect breathing life, may in a short time die: or, if the child were in a feeble or a dubious state, possessing only that life which it had during its residence in the uterus, as by tying and dividing the navelstring that life is destroyed before the breathing life is acquired, it must inevitably perish. We may therefore safely conclude, that the navel-string of a new-born infant ought never to be tied or divided, till the circulation in it has ceased spontaneously, nor would the child suffer, though the funis was never tied, if it was not divided.

With respect to the manner of tying the navel-string there has also been much difference of opinion, whether there should be one or two ligatures, and in what part these should be fixed. Two ligatures were advised on the presumption, that by the end of the funis next the placenta the maternal blood might be discharged, and the parent brought into great danger, as if there were two currents of blood circulating in the vessels; and by some it was also supposed proper to use two ligatures, for the purpose of retaining the blood, presuming that the placenta would be cast off more commodiously, in the manner of a gorged leech. On the contrary, one ligature has been recommended, that we might have an opportunity of draining away as much blood as possible from the placenta, by the divided end of the funis, which was supposed to produce an advantage equal to the diminution of the bulk of the placenta, and to favour its expulsion. But, if the custom of deferring to make the ligatures till the circulation in the funis ceases be established, all this reasoning in favour of one or two ligatures will fall to the ground. 
Yet, as there is a possibility in the case of twins, with a single placenta, of the child yet unborn losing its blood by the divided funis of that which is born, and from the habit of using them, on the whole, I prefer two ligatures, more especially as no harm can arise from them, even if one should be useless'.

Denman was a strongly made man of moderate height and with a fresh vigorous complexion, bright blue eyes, and white hair. In character he is described as cheerful and amiable, unassuming and modest, hardworking, deeply religious and an attentive benefactor to the poor. In 1770 he had married Elizabeth Brodie at the age of 37 . There were three children: a son who eventually became Baron Denman as Lord Chief Justice, and twin daughters, one of whom married a distinguished physician, Dr Matthew Baillie, and the other an equally distinguished obstetrician, Sir Richard Croft, who became Denman's associate in practice. Indeed it was with Croft that Denman planned an institution for the reception of the infants of women who were engaged as wet-nurses, for he knew how often such infants were neglected with fatal outcome. ${ }^{4}$

In 1815 Denman died at the age of 82 and was buried in St James's Church, Piccadilly. Let his injunction to his colleagues in 1880 be his epitaph:

'It must, however, be acknowledged that all the errors of practice do not proceed from ignorance of the art. Some of them may justly be imputed to our entertaining too high an opinion of the art, or too much confidence in our own dexterity, or too little dependence on the natural efforts and resources of the constitution'.

1 Denman T. Aphorisms on the application and use of the forceps and vectis in preternatural labours, or labours attended with haemorrhage or convulsions. London, 1783.

2 Denman T. An introduction to the practice of midwifery. 3rd

3 Spencer HR. The history of British midwifery from 1650 to 1800. London: John Bale, Sons and Danielsson, 1927.
. 4 Still GF. The history of paediatrics. Oxford: Oxford University Press, 1931. 